\title{
DIGITAL KANBAN BOARDS USED IN DESIGN AND 3D COORDINATION
}

\author{
Ralf-Uwe Modrich ${ }^{1}$ and Bruce C. Cousins AIA ${ }^{2}$
}

\begin{abstract}
The hypothesis of this research is that the Last Planner System ${ }^{\circledR}$ (LPS) in combination with the Kanban Method is better suited than conventional project production planning and controls to manage the design phase. In the Toyota Production System (TPS) the Kanban (sign board) is attached to the material or product and is pulled through the manufacturing process. In design and product development the Kanban is attached to the information or knowledge and is pulled through the design process. In the presented case studies, the authors developed several prototypes of a Kanban board. One is used in architectural design and in pre-construction processes to manage the 3D design and 3D coordination process and another is used to manage the design issues in an integrated and concurrent design process. The physical Kanban board displays each stakeholders' tasks across multiple swim lanes, so the team can readily assess the task assignment and work in process (WIP), of team members in one glance. The physical boards are kept up to date with digital Kanban Boards. These Kanban applications facilitated "real time" synchronization among stakeholders for monitoring of both current and future activities (look ahead) and delivering promised design decisions for information required by upstream customers. In two of the case studies the LPS was used as the initial planning tool to develop a phase pull plan to define milestones, develop a design cycle plan and establish a design phase constraint log. The combination of LPS metrics with Kanban board metrics resulted in eliminating schedule uncertainty and improved information flow including less latency of the delivery of designbuilder's work. The Kanban method was also found to be more agile than purely the LPS for managing the circular iterations of design decisions. These benefits also resulted in acceptance by design professionals to use a Lean design management approach.
\end{abstract}

Keywords: Kanban, work in process (WIP), agile, burn-down-chart, communication systems, design management, design/build, integrated project delivery, IPD, concurrent design

\section{INTRODUCTION}

The LPS offers many valuable production planning and control principles and as applied to both design and construction, in practice LPS has become the de-facto management approach for highly technical and collaborative projects. However, stakeholders in the design phase have found it to have limitations.

The primary limitations of LPS is the iterative nature of design. This results in work stacking due to concurrent design activities. It creates a shift in priorities and a redirection of production resources.

Traditional design phases of schematic design SD, design development DD and construction documents CD evolved and became a standard of practice for measuring the completion of design deliverables. The sign-off process to meet design hand-offs is outdated and too narrowly defined sequence that is no longer applicable in a concurrent design approach. A hand-off occurs whenever we separate knowledge, responsibility, action and feedback (Ward A. 2007). The traditional handoff points are now defined as

\footnotetext{
${ }^{1}$ Sr. Project Manager WEBCOR BUILDERS, 710 N. McDonnell Rd SFO T1-BAB Project T. 510-825-0358

${ }^{2}$ Principal, Sword Integrated Building Solutions, 125 2nd Street \#606 Oakland, CA 94607 Phone (510) 3092003
} 
Level of Development (LOD). LOD defines model geometry with three of the most common uses of design deliverables in mind - quantity take-off, 3D coordination and 3D control and planning. We will use this nomenclature to describe the information flow in the case studies. [see http://bimforum.org/lod/]

Although, the Lean Product Development System the equivalent in product design uses "pull" to sort through a vast amount of data to get the right information to the right engineer at the right time (Morgan \& Liker, 2006). Knowledge is the fundamental element (material) in product development and design. Current scheduling software, which do not effectively account for circular logic that naturally occurs during the design phase. Designers are not motivated to meet scheduled tasks until design solutions are optimized considering integrating overall system needs.

The LPS provides stakeholders visibility of the overall design phase plan that defines milestones, develops a design cycle plan and establishes a design phase constraint log. It creates a picture of the desired flow of information, knowledge and design decisions required to complete upstream activities (permits, materials orders and other items).

The Kanban method pulls the work through as the Kanban signal is generated. Like the LPS it also makes the work visual both workable backlog and WIP. Kanban is a flexible tool and allows adjustment of work on the fly. Progress can be measured as unplanned tasks can be added to the board. Reasons for variation are not as important as the visual effect of seeing new unplanned work or unresolved constraints on a design solution's completeness.

The visibility of constrained items focuses the team on resolving issues sooner and encourages discussions about pivoting and/or finding the best solution - not the perfect solution.

\section{BACKGROUND}

Generally, in a manufacturing environment, units are transported to the next production stage, as soon as they are ready. Kanban, meaning signboard or label, is used as a communication tool in this system (Imai M., 1986) Ohno, reversed this, so that each stage was required to go back to the previous stage to pick up the exact number of units needed.

In the Toyota Production System (TPS), Taiichi Ohno (1978) defines six rules for a Kanban system:

1. Customer (Downstream) processes withdraw items in the precise amounts specified on the Kanban. Kanban serves as a withdrawal order, an order for conveyance or delivery.

2. $\quad$ Supplier (Upstream) produces items in the precise amounts and sequences specified by the Kanban. It serves as a work order.

3. No items are made or moved without a Kanban. It prohibits picking up or producing goods without a Kanban.

4. A Kanban must accompany each item, every time. It is required to be attached to the goods.

5. Defects and incorrect amounts are never sent to the next downstream process. 100 percent defect free products.

6. The number of Kanban is reduced carefully to lower inventories and to reveal problems. This way a Kanban prevents overproduction.

Kanban cards usually signal (control) production in a pull system. In product development and design, knowledge and information are the materials that are required by the downstream activity (Morgan \& Liker, 2006). Tactile properties have been less 
researched, though important industrial applications have been developed. The Kanban system uses physical placement of documents (cards or tags) to facilitate improved production flow (Rooke, Koskela \& Tzortzopoulos, 2010).

A digital Kanban Board offers managers a variety of measures that assist in interpreting and managing the flow of a project team's activities. The metrics of Kanban are expressed in velocity, flow efficiency, and throughput, WIP flow through the board. A cumulative flow diagram (CFD) offers managers an understanding of activities that are flowing through the board. CFD is a visual representation of when an activity starts moving from backlog to WIP to review, to done or returned to the backlog of work for later activity, or advanced to an accelerated completion or finally to done. The project team agrees to limit WIP based on their capacity to complete the work. WIP is adjusted daily and or weekly to represent the estimated and actual man-hours required to complete activities. The measured "Cycle Time" to complete activities assists the project team understand both current demands and predict future completion or throughput trajectories. Because the board is visual the cumulative effects of flow of activities are visible to the project team and allows for rapid improvement and adjustment in the PDCA cycle. Adjustments are made to limit WIP as the project proceeds.

\section{CASE STUDIES}

The first case study is the design \& engineering of support infrastructure of a semiconductor manufacturing production line for a manufacturing facility for a confidential client. The Lean Design management consulting company Sword [1] established and implemented a Kanban System to improve the information flow of the integrated project team both during the planning and design phase (LOD 100-200) and the production of spooling documents (LOD 300-400). The second case study is the architectural design phase of the San Francisco International airport Terminal 1 rebuild. It is a $\$ 630 \mathrm{M}$ project with Woods Bagot [2] in a design joint venture (JV) with HKS Architects. The design JV uses a digital Kanban board to manage information flow and knowledge distribution on the project. The WB-HKS JV has been using Trello Kanban software since the end of the Design Development. Woods Bagot uses Kanban boards on all their projects of the San Francisco and New York office.The third case study is the same project as the design joint venture, it is the Terminal 1 Boarding Area B of the SFO airport. Webcor Builders [3] is in a joint venture with Austin Industries (AWJV) representing the General Contractor on the project. The project is a public project therefore using an IPD type contract is not possible yet but the contract is a design-built contract with a collaborative spirit. The airport has the intent to run the project as much collaborative as possible in the public environment with the full spirit of IPD. Subsequent an airplane hangar was built out to create a collaborative work space for the project teams of Terminal 1 Central and Boarding Area B. This space houses the two design teams, the two general contractor teams and all the core trades. The space is called "The BIG ROOM" and is located on the SFO airport property.

\subsection{Methodology}

This research can be classified as constructive research. This approach aims to generate scientific knowledge, developing an artefact to solve a real problem (Holmstrom et al.2009). Despite their different underlying philosophies and controlling mechanism, the authors put forward the proposition that there are benefits of integrating LPS and a Kanban method. 
In all three case studies the initial framework for all the work was established based on BIM with a Model Progression Specification (MPS) Matrix. The MPS Matrix is the equivalent of a "Story-Board" as used in Agile Software development, a framework for the project. The matrix which overlays a project's building systems in one axis over the time frame of the project on the other. The BIMForum LOD specifications definitions are used by the project team to establish the agreed level of completion of the different system modelling for "fixing" the elements and handing off to upstream customers. Optimally, the project team would engage pull planning sessions to define different information flow pathways. The outcome gives an understanding when the different BIM for building systems must be completed by the design team and at what LOD level it is necessary to dovetail with the production team's responsibilities to support buy-out, permitting, premanufacturing, supply chain and construction flow.

\subsection{Kanban Use in Design}

The key to get the right process steps is to value stream map current practice. The individual steps defined by the process map are the activities represented by the Kanban cards that will be placed on the Kanban board. In early design activities, depending on the project type, these value streams are incomplete or very chaotic. Initial efforts undertaken by a project team often serve to define knowledge gaps and other missing information and decisions that will be needed later as the team moves from the problem definition stage of programming to the problem-solving stage of design.

The problem statement, then, is the interface between programming and design (Peña, Parshal, 2001). In the beginning, they are manually represented on a Kanban Board physically located near the project team's workspace. Initially, they serve to define both known information as well as information gaps. Often when the project team maps the value stream, the team will attempt to recast the value stream to reflect the initial or contracted sequence presented in the Master Schedule. This tendency to recast the project to fit contractual arrangements must not be allowed the VSM must reflect a true picture of the actual process being used. (Anderson, 2010).

To map the value streams the teams use the pull planning methodology of the LPS. In ad hoc meetings where cross-functional team members value stream map the steps to solve a problem, post-it notes are used to agree and write down the process steps and the right flow of the information to solve a specific problem. The tactile part of discussing and writing, and posting it to the wall has psychological benefits. Putting the process steps into a digital system is not a wasted overproduction, it has various benefits. First, it instantly becomes visible to the entire project team, second it is in the system so the process is recorded and if a similar problem arises, the process steps can be re-used without the necessary re-mapping of the value stream. Third applying the standardization thinking opens the opportunity to improve on the process, e.g. necessary re-sequencing and better understanding what level of effort it takes to execute the steps.

As mentioned above the initial framework is set by agreeing on the deliverables and defining a MPS-Matrix in the BIM execution plan (BIMex). Teams - Architects, Engineers, specialty trades, General Contractor and Owners or their representatives are responsible for establishing target budgets and controlling costs and fulfilling design intent objectives and schedule. The clusters independently define design program and then present design solutions that through experience and performance results are most suited for the stated goals and objectives of the project.

The short term iterative processes of solving various problems in design are mapped and undertaken by the project team clusters in short cycles or "sprints". The products of 
a sprint are evaluated in relation to overall goals, objectives and target budgets. The tasks required by the team in these short-term intervals are listed on the Kanban. The Kanban board provides an actionable schedule of tasks required to make decisions and highlights critical interdependencies of decisions. The learning generated in a cycle is documented on an A-3 placemat. This is analogous to sprint-planning in Scrum in an agile software development.

A sprint allows the project team to rapidly assess the viability of partially developed alternative solutions, discover and visualize constraints and test assumptions. The sprint methodology gives the collaborative project team just enough information that can be used to indicate if they should proceed to develop a design solution further or pursue a different line of thinking. Should the team decide they would need to change course, the team then may send the issue back to be reworked. This is known as a "pivot".

The velocity of decision making is displayed so that all can see the flow of decisions, information gaps and critical co-dependent relationships of information required for a design team to progress the project to meet schedule and budget milestones. The Kanban cards are very visible and their tactile nature offers the project team - including the Owner -- visual clues regarding deliverables and key decisions changes as the board physically appears different (Hiranabe, 2008). In the environmental, architectural, and product design fields, for example, there is a focus on specific user related knowledge such as graphical information, architectural clues and other forms of visual and tactile cues (Arthur \& Passini 1992).

\section{FINDINGS}

\subsection{Kanban System in Design}

\subsubsection{Kanban in Design \& Engineering}

The first case study is the design \& engineering of support infrastructure of a chip manufacturing production line for manufacturing facility for a confidential client. A basic use case for the Kanban Method is in the early stages of Design. The owner required the project team to utilize a collaborative integrated approach for the design phase (LOD 100200) of the project. The design engineer was also responsible for creating spooling drawings (LOD 300-400) for the infrastructure rack below the manufacturing level. See Figure $3 \& 4$ following.

As more of the engineers designers and technical personnel became involved in the project it became increasingly difficult for everyone to schedule and balance the design team work loads, status owner and trade signoffs and generally maintain the flow of both the design engineering and spooling throughput. The design engineer team at the direction of Sword established a digital Kanban Board. It was decided that the Kanban method would make transparent the tasks required to complete designs and visualizing of the activities would allow the project team to more effectively status both the information and the activities needed by a design team to complete team or design problems.

The project was first divided into multiple smaller batches based on the construction team's plan; LPS established the needs of upstream players, Figure 2. This step confirmed master schedule milestones. The project's intermediate milestones were adjusted and the major milestone durations were refined and optimized.

Handoffs to trades for fabrication had the highest priority and all critical dates included the Kanban cards. This made visible both, the information and work products needed to get "fixity" and deliver the designers work products to purchasing and delivery by the 
trades. The Kanban was also used by the designers to level the work load among in-house producers, inform them of the work backlog and the WIP, allowing the design team to prioritize and manage the deliverables on a daily and weekly basis.

1. The Designer found that they could rapidly rebalance production engineering and drafting/modelling manpower as the client's scope changed, enabling them to pivot between design and spooling tasks more efficiently.

2. Both the project's designers and trade partners reported that "problems" with spooling documents didn't make it to the field.

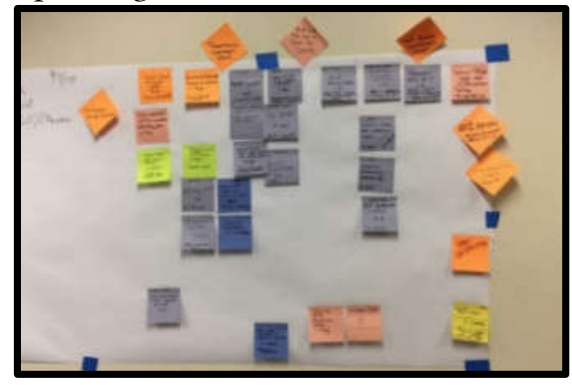

Figure 1: Pull Plan - (LOD 300-400)

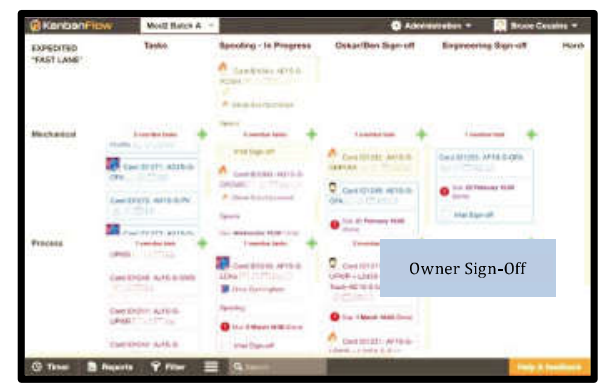

Figure 2: Kanban board - (LOD 300-400)

\subsubsection{Kanban in Architectural Design}

Case study two shows the use of a Kanban system in the architectural design phase. The architects are using a digital Kanban board to manage information flow and knowledge distribution on the project. Initially there was a slow adoption of the Kanban method because of the reluctance to introduce a management system, but quickly the team realized that they could easier visualize and communicate their design tasks between the two firms and their consultants. The team found it beneficial using the introduced LPS customs of writing the task requester, performer and clearly defined actionable description on the cards. Daily stand-up meetings in the design clusters and weekly meetings with all team members reviewing the board items ensured the alignment of short and long term goals of the project.

The digital board created a project wide transparency and better overall communication between owner, construction manager and the designers. Woods Bagot has standardized their Kanban board to address three types of Kanban, these are information, knowledge and decisions. The milestones in the board visualize the progress toward them and have been built according to the project Model-Progression-Specification (MPS) Matrix. The MPS is showing their design deliverables developed around the framework of LOD. In this case study the team is using Trello to manage their Kanban see Figure 3.

\subsection{Kanban System in 3D Coordination}

The third case study is also taken from the SFO airport Terminal 1 project. This case study focuses on another use case for the Kanban Method in design and preconstruction phases of the project. In 3D Coordination LPS thinking is used to develop the basic location based schedule. The location break down structure (LBS) of the construction is followed in 3D coordination. Pull Planning Sessions develop the coordination plan working from construction back to the point when, which system and area must be modelled to a LOD 350 so 3D coordination with clash detection and clash avoidance on composite 3D models of all systems is ready. 


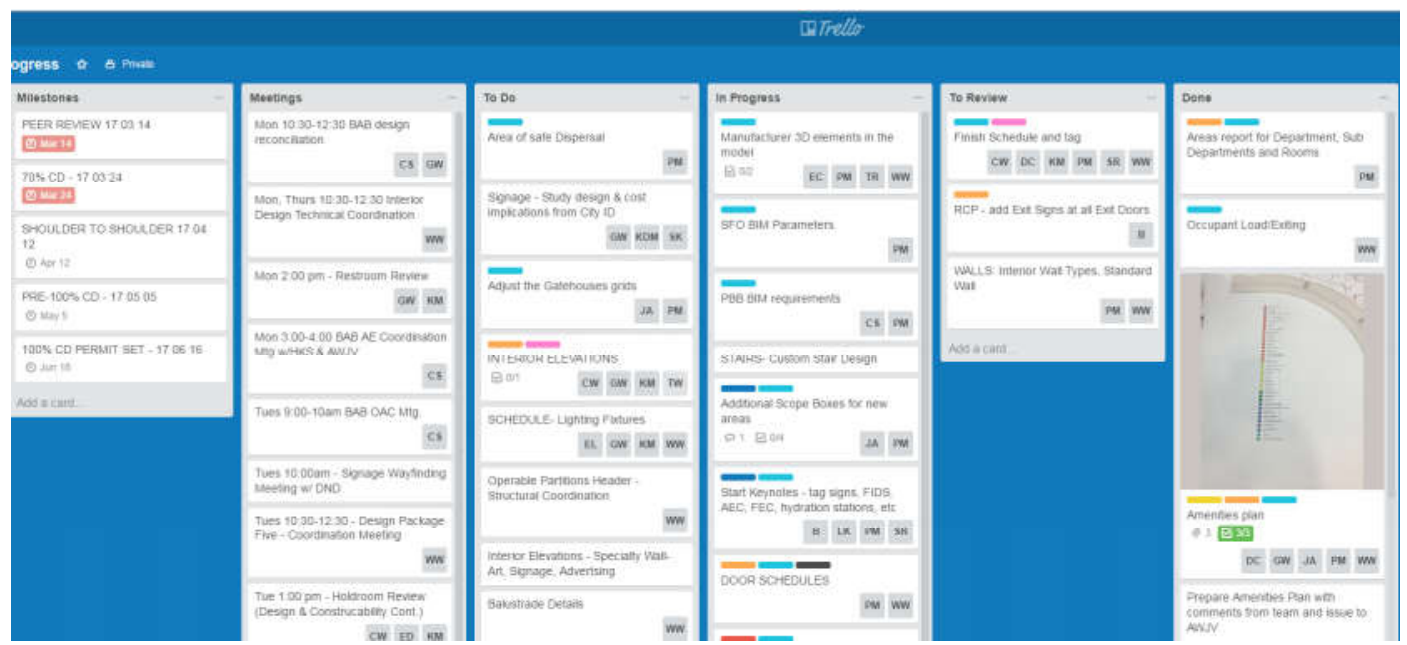

Figure 3: Design Kanban board

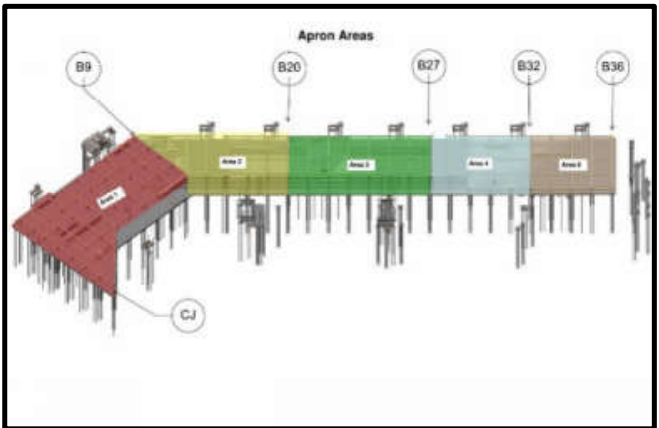

Figure 4: Location Break Down BIM

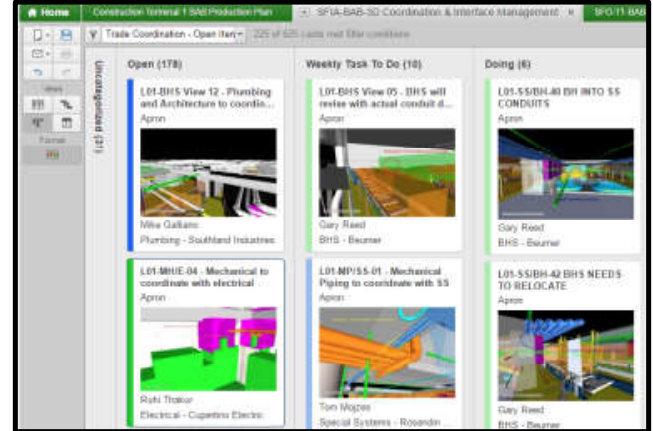

Figure 5: 3D Coordination Kanban Board

The Kanban has an assigned trade with a designated building system colour, a performer and the actionable task description, see Figure 5. That column becomes the committed plan like the weekly work plan in LPS. The actual point in time before somebody executes the committed Kanban he/she moves the card into the doing column and after he/she is done into the "Done" column. The Kanban Board helps the team understand how they are doing as well as what to do next. (Hiranabe, 2007). This in combination with the cloud based access of Autodesk BIM 360 Glue to the combined 3D models of all project participants, underlines the collaborative and self-directing aspects of the two technologies and creates synergies which results in faster problem solving cycles.

\section{CONCLUSIONS}

By using a Kanban in design or 3D coordination the Kanban is attached to the information, knowledge or decision and is moved up or downstream through the design process. The tool displays each designer's tasks across multiple horizontal columns or rows (swim lanes). Therefore, users can assess the task assignment and workloads, WIP, of team members in one glance. The board also links up with digital Kanban Boards -- Trello, Lean Kit, KanbanFlow, SmartSheet and JIRA. These offer the feature of real time synchronization among clients for distributed development. The digital Kanban boards have the benefit to attach data to the Kanban and after the project the knowledge is not lost like in a conventional design process. The data can be archived and later easily accessed on the cloud. The use cases showed that the proposed approach was effective. Furthermore, in 
both case studies the LPS was used as an initial planning tool to develop a master design plan as well as a look ahead plan. The combination of LPS metrics with the typical Kanban board metrics resulted in synergies and information flow improvements and less latency of the design/builders work products in the validation and design development phase of the projects. The hypothesis, that a Kanban Method when combined with a LPS is well suited to management of the Design Process, has been proven true.

\section{REFERENCES}

Ahmad M. O., Markkula J. and Ovio M. (2013). Kanban in software development: A systematic literature review. Proceedings of the 39th Euromicro Conference Series on Software Engineering and Advanced Applications, Santander, Spain

Anderson D. J. (2010). KANBAN. Successful Evolutionary Change for Your Technology Business. Blue Hole Press, Sequim, Washington, U.S.A.

Arthur, R. \& Passini, R. (1992) Wayfinding: People, signs and architecture. McGraw-Hill, New York.

Ballard, G. (2000). The Last Planner System of Production Control. Thesis (Doctor of Philosophy), University of Birmingham.

Brown, Tim (2009) Change by Design, HarperCollins Publishers, New York, USA.

Hannele Kerosuo H., Mäki T., Codinhoto R., Koskela L. and Miettinen R. (2012). In time at last-adoption of Last Planner tools for the design phase of a building project. Proceedings 20th Ann. Conf. Int'l. Group for Lean Construction, San Diego, California, U.S.A.

Highsmith J. (2010). Agile Project Management. Creating Innovative Products. Pearson Education, Inc., Boston, MA, U.S.A.

Hiranabe K. (2007). Visualizing Agile Projects using Kanban Boards. https://www.infoq.com/articles/agile-kanban-boards, posted 08/27/2007.

Hiranabe K. (2008). Kanban Applied to Software Development: from Agile to Lean. https://www.infoq.com/articles/hiranabe-lean-agile-kanban, posted 01/14/2008.

Imai M. (1986). KAIZEN (Ky'zen). The Key to Japan’s Competitive Success. McGraw-Hill Publishing Company. New York, USA.

Loeb, Jeff (2016) Lean Design Forum, Kanban Method - Application in Knowledge Work.

Morgan J. M. and Liker J. K. (2006). THE TOYOTA PRODUCT DEVELOPMENT SYSTEM. Integrating People, Process, and Technology. Productivity Press, New York, New York, U.S.A.

Nakazawa S. and Tanaka T. (2015). Prototype of Kanban Tool and Preliminary Evaluation of Visualizing Method for Task Assignment. Proceedings of the 17th ICCAT International Conference on Computer Applications in Technology, London, UK

Ohno T. (1978). TOYOTA PRODUCTION SYSTEM. Beyond Large-Scale Production. Productivity Press, Portland, Oregon, U.S.A.

Peña W., M. \& Parshall S., A. (2001). Problem Seeking. An Architectural Programming Primer. John Wiley \& Sons, Inc., New York, USA

Shingo S. (1981). Study of 'Toyota' Production System from Industrial Engineering Viewpoint. Japan Management Association, Tokyo, Japan

Ward A. C. (2007). Lean Product and Process Development. The Lean Enterprise Institute, Cambridge, MA, USA. 